\title{
Ethical map reading in neonatal care
}

\author{
Priscilla Alderson Goldsmiths' College, London University
}

\section{Author's abstract}

This paper suggests that medical ethics is often based on assumptions, commonly shared in modern medicine, which can cause problems and which need to be questioned. Two contrasting yet complementary ways of thinking about ethical dilemmas in neonatal care are described as the 'separation' and the 'attachment' approaches. The contribution of medical ethics to the substance and quality of discussions between doctors and parents is considered.

In some respects medical ethics is like cartography. Both disciplines point out the main features of a scene and the relation of various parts to one another. Principal routes can be outlined and subsidiary ones shown to be short cuts or dead ends. Yet maps can have disadvantages. They may distract the traveller from observing and understanding the landscape and from exploring new ways. When we begin to feel lost and attend more anxiously to the map, we may no longer see our surroundings clearly, but dismiss them as 'wrong' because they do not tally with the map.

This paper considers two problems which can arise in attempts at ethical map reading. The first is: How much can or should a map be used, not only in checking our way along the route, but also in guiding the intention, justification, direction, nature and goal of the journey? Medical ethics may aid our wandering but can it assert that one destination is better than another?

The second problem lies in the way maps are made. As a pattern of symbols they are a compromise between being too detailed and therefore confusing, or too simple and therefore misleading. A map is simply one way of labelling reality to enable us to move around new territory. Similarly, medical ethics lays down principles which bound our view of a dilemma, creating an abstraction which draws out the main issues and clears away the details. However, it is not always clearly agreed which are the major and minor features of any particular case. For centuries, certain central aspects of ethical dilemmas have been dismissed and I suggest that the effect has been as if we

\section{Key words}

Medical ethics; neonatal care; decision-making; informed consent. were guided by maps with no contour marks, too far removed from the realities of the journey.

There is a tendency to assume that all travellers - the experienced doctor, the sick patient and the anxious relatives - can cope equally well with the same terrain. $\stackrel{\circ}{\triangle}$ Routes over precipitous mountains, which look simple and direct on flat paper and appear to be the most logical course to take, can prove to be overwhelmingly $\frac{\Phi}{\mathcal{S}}$ difficult for some people, who need more circuitous ways allowing them time to search around other options and to come to terms with the nature of their. journey, particularly when there is a possibility of loss, of serious handicap or death for the patient. The landscape, for the family at least, may be dominated by features of their attachment to the patient, such as sorrow, guilt, anger or ill-founded hope. These may $\stackrel{\mathbb{}}{\propto}$ need to be 'worked through' and key ethical issues are $\overrightarrow{\vec{B}}$ how the patient, the family and the staff caring for $\frac{0}{3}$ them can best be guided and supported through their experience. It is possible that each participant's view of a single shared experience will differ so much that, for some, a narrow ethical summary and guide will be $\bar{\varsigma}$ inappropriate and unhelpful; a way foward which $\overline{0}$ looks clear and rationally chosen to some people, to others may look unendurable.

If informed consent were simply a matter of intellectual understanding, the process of negotiating 은 consent could be confined to rational discussion about $>$ which course is the most logical one to take. But informed consent to medical procedures also includes a voluntary component involving the will, aspirations, $\infty$ personal values and a range of feelings all of which alter $\tilde{N}$ our individual interpretation of logical arguments, our $\underset{\mathrm{W}}{ }$ perception of which is the wisest course to take, and $\mathcal{Z}$ our readiness to pursue that course.

However, cartesian cartographers concentrate on $\frac{D}{\Phi}$ reason, logic and fact but omit feeling, intuition and $\stackrel{\odot}{+}$ aspects of experience which are dimensions inherent in 7 ethical dilemmas although ignored by many philosophers. This limits their vision and reasoning, $\stackrel{\mathbb{Q}}{\stackrel{\oplus}{\mathscr{Q}}}$ and I think makes their contribution to questions such $\stackrel{\mathbb{Q}}{\Omega}$ as the autonomy or the best interests of patients $\overline{-}$ sometimes an attack against, rather than a defence of, the patient. You may consider that medical ethics is neutral and should not favour or defend any one group. Yet there is an imbalance of competence and autonomy $\frac{\bar{c}}{\partial}$ 
in a medical setting between, for example, a paediatrician and a sick baby, and also between the doctor and the baby's parents; the scales are tipped and any contribution to discussions about the patient's best interests will affect the weighting. Doctors and patients, or their relatives, may aim towards a fair sharing of knowledge and authority, and a shared commitment to decisions, but who will agree on exactly where such equity lies or how it is achieved? Where there is a difference, even a conflict, not only of values and intentions but also of the means of representing and understanding certain viewpoints, it would be appropriate for medical ethics to clarify difficulties arising from the differences rather than to share the unquestioned assumptions of any one single group.

\section{Beneficence to babies}

An example of confliciting modes of thought is presented by the contrast between a generally maternal response to babies and the approach advocated by medical ethics influenced by Kant's categorical imperative: 'Act only on that maxim through which you can at the same time will that it should become a universal law' (1). This suggests an impersonal, rigid response to all people as if they were the same and that what we want for ourselves will be the same as what others want for themselves; yet babies and philosophers differ greatly in their needs. Although it may be said that principles must be general while people remain individuals, Kant implies adherence to extremely rigid and impersonal principles.

'I need no far-reaching ingenuity to find out what I have to do in order to possess a good will' (2). 'In morals the proper worth of an absolutely good will, a worth elevated above all price, lies precisely in this that the principle of action is free from all influence by contingent grounds, the only kind that experience can supply. Against the slack, or indeed ignoble, attitude which seeks for the moral principle among empirical motives and laws we cannot give a warning too strongly or too often' (3). 'The practical necessity of acting on this principle - that is, duty - is in no way based on feelings, impulses and inclinations but only on the relation of rational beings to one another' (4). 'We should not act from our own interests or from another's but from "the supreme principle of duty" ' (5).

These statements are extraordinarily impersonal and detached. They may describe the principles on which a professional relationship could be based but this attitude within a personal relationship, such as a mother caring for her baby, would look pathological. Kant seems to be telling us to attend to the map of duty and to follow the directions of the map for its own sake. The result, far from the intended treatment of persons as ends in themselves, would be to treat them as means of performing pre-ordained duties. Kant sees beneficence, for example, not as something shared between two people, but as something impersonal; 'the giver and recipient have a certain distance from, and stand external to, one another' as if beneficence 'could be a good for anybody and which could, as it were, be given by anybody', but what makes a personal kindness good is that it is a personal good between two particular people (6).

A mother might say that her feeling about her baby is one of sympathy and of 'far-reaching ingenuity' attempting to appreciate the baby's point of view, guided by attention to him or her and responding spontaneously and warmly, not as the puppet of cold duty as laid down by others. Mothers and babies learn through a shared thinking and feeling experience, influenced by contingent and empirical grounds, learning to trust their own assessments as the unique relationship develops. Kant seems to be afraid of human relationships and so he distances and controls them through the impersonal third party of duty. Complications arising from relationships, both the emotional difficulties and the ethical conflicts, are left out of Kant's map. He admits no conflict between will and duty and no division of personal loyalties. How can medical ethics based on this kind of false simplicity guide discussion on, for example, how the interests of a profoundly handicapped baby and also of the baby's family may best be served?

\section{Two ways of thinking}

Ways of thinking about moral problems can be divided very broadly into two kinds, illustrated by the difference between the Kantian and the maternal views. These may be briefly described as the separation and the attachment approaches, which are based on fundamental, often unconscious assumptions (7). Separation thinking tends to see safety and success in independence, and autonomy as a matter of respect and rights, trusting to one's own resources rather than depending on others and thus falling into a threatening vulnerability. The attachment approach tends to see human life as a network of relationships, connections which create trust and security. Too much independence is dangerously isolating, and expresses disregard for others, whereas respecting autonomy involves relating to others within an ethic of care.

These two approaches to life become the bases of two distinct methods for resolving problems (7). Separation thinking aims at detached objectivity, an impartial search for truth or justice, for example, in mathematics, logic and scientific discovery, in resolving legal disputes and in the fair allocation of resources such as in hospital administration. Problems tend to be analysed as an equation of priorities and rules with reference to precedents and principles or, in other words, to maps already drawn up by experts as a general, impersonal guide. On the other hand, attachment thinking is concerned with the particular case, with compassionate, subjective involvement, with awareness of the complexity of human dilemmas and their far-reaching later consequences, of the need 
for flexibility, negotiation, and changes in understanding depending on contingent issues. Contingent means touching; the concentration is on the individual concerned and all the issues relating to this particular case, rather than looking aside at general guidelines.

While detachment is a necessary part of scientific or logical excellence, attachment is part of human relationships; ethical dilemmas in medical care, involving both science and humanity, require both detached and attached understandings for their resolution. Yet the emphasis of much teaching in medical ethics is on detachment alone: 'To try to arm you with a toolkit of principles or schemes for analysis ... a framework of rules . . . so that you can analyse [a problem] in abstract terms and say this is an autonomy problem or this is a justice problem' (8).

Now although a toolkit can be most useful, as with a map it needs to be used with discrimination. A framework of rules based on separation thinking, which reduces a problem to 'abstract terms', not only cannot address all the relevent issues in a human dilemma, but also enforces a narrow vision of concepts such as 'justice' or 'autonomy' or 'the person' which, particularly in neonatal care, can increase rather than resolve difficulties. (There is not space here to examine the more involved definitions arising from attachment theory, or how they may be more relevant for patients who are regarded neither as autonomous nor, by some philosophers, as persons.) My question is: why should Western medical ethics be so dominated by separation assumptions, for example, such as those evident in its prescriptions on how to frame, define and analyse problems, in its attempts to reduce human complexity to clear logic, in its concentration on equations of relative utility, and in the slight attention paid to examining those medical, nursing and administrative systems which cause (possibly minor but) unnecessary distress?

One reason is that much of Western science, technology, medicine, law and philosophy has traditionally treated types of experience as clear entities to be defined, measured, controlled and organised. Without detached attempts to stand outside the subject matter in order to assess it clearly and purposefully, modern intensive medicine would probably be unimaginable. So also would mass health care with its benefits being complemented by the disadvantages of undue detachment - impersonal and rushed treatment, when health service staff expeditiously herd patients through the system. The staff are constrained partly by the health service resources allowed to them, and partly by having to protect their inner resources from being drained by the endless needs of strangers. Detached thinking is the dominant mode of thought in our society, but it is disappointing when medical ethics shares, rather than questions, its assumptions, attempting to cover over the confusion of personal dilemmas and values with an edifice of virtuoso logic. As George Eliot wrote:
'We have no master key that will fit all cases [of moral $\underset{\overrightarrow{7}}{\overrightarrow{0}}$. decision]. The truth to which eyes and hearts are too fatally sealed [is] that moral judgements remain false and hollow unless they are checked and enlightened by $\stackrel{S}{?}$ a perpetual reference to the special circumstances that mark the individual lot [and] are informed by growing insight and sympathy' (9).

If we are guided by this kind of attachment thinking, more attention is paid to the quality of care. Our eyes $\overrightarrow{0}$ and hearts come to understand that we cannot stand completely detached from the experiences of others or $\vec{\omega}$ from our effects on them and that it is impossible to make moral decisions without becoming involved with more than the rational aspects of the circumstances.

\section{Sharing responsibility}

In medicine, unlike philosophy, practical decisions have to be carried out all the time. A medical ethics which is too pure and impractical can hamper already painful, difficult discussion of individual cases; if it is too direct it may force discussion prematurely and not $\stackrel{\widehat{O}}{\mathrm{~S}}$ in helpful directions. I suggest we should beware the hubris of ethicists who are too certain about the ends as $\infty$ well as the means of making decisions for a particular patient.

There are times when it is more important to travel than to arrive. By this, I do not advocate prolonging agonising indecision and suspense but I do want to stress that the manner in which a decision is made may be as important as the conclusion. For example, medical treatment is not just a brief technical procedure, the province of experts, it is a gateway to a future of better or worse health, or sometimes death, in which the patient and/or family carry the knowledge and responsibility. In neonatal care the future is potentially a whole lifetime including many years of dependence on the family. Although it is sometimes claimed that parents prefer doctors to carry responsibility or blame for fatal decisions about their child, not all parents may agree with this. Whether the baby lives or dies, the parents have to live with the outcome of the medical decision for a very long time; it may be easier for them to bear the gain or loss if they $N$ know they had at least a fair opportunity to agree to any interventions. Being a parent or a doctor is a matter of trying to do one's best for the child; many parents need to feel that they were able to fulfil their obligations, anci that through being involved they saw that allo concerned were giving reasonable time and attention $t$ the child's interests. Through their personal ? attachment, parents can temper medical detachment; both ways of thinking are required in wise judgement.

Quite apart from the points made, the way in which they are made, whether they are encouraged 0 ignored, the very quality of the journey of decision making, can become as important as the goal. 1 involving parents in decision-making is take seriously, attention has to be paid to the many barrier which can lessen or prevent parents' involvement ir 
neonatal units: difficulties which keep them away such as expensive fares, or that inside the hospital there may be no space to sit near their baby. And there are invisible barriers such as their anxiety, or their reluctance to talk to busy staff, besides the many extra difficulties for the staff, of working with distressed parents. All these factors affect the quality and results of discussions shared between parents and staff, and key ethical issues are how the inherent barriers may be overcome and unnecessary barriers discarded. Involving parents may then not only serve their own child, but also other children by changing the character of the neonatal unit and of those working in it. This reverts to the original meaning of the word 'ethics' as having to do with character, before it dwindled down to a concern with morals and manners, until now it seems only to relate to the habit of turning to detached experts to prescribe answers to isolated dilemmas.

Medical ethics can help to illuminate the main considerations of a dilemma and how they are related within the work of the neonatal unit and the life of the patient and family. Ethics can be a valuable aid if it does not confuse issues with esoteric argument or summarise complexities with false simplicity, if it helps the staff and parents to see each other's view more clearly, and if it is informed by an understanding of attachment thinking as well as detached reasoning. Acknowledging the emotional contours during discussion can serve the further purpose of bringing those concerned together towards an agreement. It can help to reconcile them to the final decision and its consequences and can often help them to change during this time. One effect is to alter practice in neonatal units in order to promote harmonious family relationships which are beneficial whether the baby lives or dies.

\section{Acknowledgement}

The author gratefully acknowledges the help of parents and staff at the Brompton Hospital, and the Hospital for Sick Children, Great Ormond Street, London.

Priscilla Alderson is a postgraduate research student at the Sociology Department, Goldsmith's College, London University. She is funded by the Economic and Social Research Council.

\section{References}

(1) Kant I. Groundwork of the metaphysic of morals. In: Paton H J. The moral law. London: Hutchinson, 1948: 84.

(2) See reference (1): 68.

(3) See reference (1): 89.

(4) See reference (1): 96.

(5) See reference (1): 95.

(6) Blum L A. Friendship, altruism and morality. London: Routledge and Kegan Paul, 1980: 57.

(7) Gilligan C. In a different voice. Cambridge, Massachusetts: Harvard University Press, 1982: 25-63.

(8) Kennedy I. Commentary 4. Fournal of medical ethics 1984; 10: 206.

(9) Eliot G. The mill on the Floss. New York: Signet, 1965:521.

\section{News and notes}

\section{Philosophical Ethics in Reproductive Medicine}

An international conference on Philosophical Ethics in Reproductive Medicine will be held at the University of Leeds from 18-22 April, 1988.

Guest speakers include Professor G R Dunstan, Professor of Theology, University of Exeter, Professor C Grobstein, Department of Biological Science and Public Policy, University of California, USA, Dr R Gillon, Editor, Fournal of Medical Ethics, Mr R Snowden, Director of the Institute of Population Studies, University of Exeter, Mr S Lee, Lecturer in Law, King's College, London, Dr
Ann Fagot-Largeault, Department of Philosophy, University of Paris.

Topics will include: Moral position/status of embryo; randomised trials; withholding neonatal care; resource allocation; termination on grounds of preferred sex, and sterilisation of the mentally retarded.

For further information please contact: Director of Continuing Education, Department of Adult and Continuing Education, The University, Leeds LS2 9JT, UK. 